\title{
Model of nuclear energy valuation in the context of e-mobility
}

\author{
Greta-Marilena VITIOANU \\ Doctoral School in Business Administration, The Bucharest University of Economic Studies, \\ Romania \\ vitioanu.greta@yahoo.com
}

PICBE |

1227

Ileana GAVRILESCU

Doctoral School in Business Administration, The Bucharest University of Economic Studies, Romania

gavrilescu.ileana@yahoo.com

\begin{abstract}
Due to the depletion of fossil fuels and the degradation of the ecological balance, the transition of mobility to new ways of propelling means of transportation is one of the toughest themes of sustainability, debated as such and by scientific research. At the same time technological research has already proposed several forms of vehicle powering and the manufacturers have even offered the market a significant number of electrically propelled vehicles - the option with the greatest technical and economic potential for everything that will mean future transportation of people and freight. Unfortunately, the development of electrical mobility to its quasi-state is dependent on increasing the capacity of supplying enough electricity from the power industry. The objective of our study is to develop a model for the utilization of nuclear energy in view of the global expansion of e-mobility applications. In the context of increased demand for electricity - due to new e-mobility technologies and applications, nuclear power can become the most efficient and constant form of electricity generation. The research methodology is based on qualitative analyzes of new $e-$ mobility applications and their diversification tendencies, but also on quantitative analysis based on a specialized questionnaire. The novelty of the research finds its exemplification in attempts to explain the importance of nuclear energy in the new context of climate change and at the same time proposing a hypothesis regarding the possible maintenance and / or refurbishment of nuclear power plants.
\end{abstract}

Keywords: nuclear energy, e-mobility applications, electric vehicles, electricity generation, climate change.

\section{Introduction}

The world of today faces several major problems, one of which is the concrete trend of the whole world wanting to have a higher standard of living, according to the new technology offerings - of the fourth industrial revolution, but especially the desire of an important part of the global population that still has to recover the difference between poverty and the Western living standard. The Western standard of living is unanimously regarded as ideal, and maintaining this ideal - for some, and reaching it - by others, implies, among other things, the increase in energy consumption. Some forecasts show that global demand for energy will increase by over $80 \%$ over the next 25 years.

Unfortunately, there are two major issues that are against the attainment of this ideal. One is the tendency to exhaust fossil resources (coal and oil), which are the main fuels of the most important traditional power generating technologies, and the other is the exhaustion and deterioration of other natural resources such as air, soil and water which are vital and define the balance of "man-nature".

Climate change, causing major disasters, is obviously a consequence of bad exploitation of natural resources during the first three industrial revolutions known in history. Adding up the illness or death of millions of people, caused by chemical, biological 
and physical pollution, it results in a somewhat sinister image of the effects of "unsustainable" development.

Affected in its core, mankind seems to wake up in the twelfth hour. Now mankind has to fight on many fronts. Economic science - the most culpable of the rebel economic offensive (according to the beliefs of many scientists, politicians and personalities from the widest spheres), is the first called to support the redirection of the new front.

Traditionally, electricity is produced by combustion of fossil fuels, water fall and nuclear reaction. To meet the increasing demand for electricity, besides traditional sources, they are called to participate in the global electronergy mix and so-called "renewable" or "clean" sources. In 2015, the International Energy Agency has set the 2020 renewable energy ratio to reach $26 \%$ of world production and $20 \%$ of EU consumption by 2020 (IEA, 2018) for the energy map.

On the other hand, the technologies of renewable energies - wind, solar, biochemical, geothermal, hydraulic, can not yet cover the current electricity needs neither as a volume of supply nor as continuity. And the discontinuity means the lack of stability in the power system. In this context, particular attention is paid to nuclear energy, which seems to be the most consistent with all the desires.

From the increasing demand for electricity needed to continually improve the quality of life, a particular demand is made up of the need for electric cars to charge their batteries.

"But what would be the most potential energy source in all technical, economic, social and ecological aspects?" is a question whose response depends not only on the interest of research but also on the whole of society. Instead, an answer to the question, "Which of the power sources enjoys the greatest sympathy and public acceptance when it comes to the massive adoption of electric cars?" Is a question whose answer can be extremely useful to research. Our conviction is that only an evaluation model - by its unitary and synthetic nature - could "surprise" the truth. All countless data, looks, answers and results could be concentrated in a meaningful formula.

Nuclear power is one of the sources of power generation without impact on the environment. Nuclear power can easily stand near renewable energy sources, as "clean" ways of producing electricity (Soo-Ho Park, et.al., 2016). The assessment of nuclear energy - by proportional values compared with the values of other energy sources, will reveal its relative advantages and disadvantages. The value given by a model of evaluation of a power source would use the entrepreneurship in the field, politics and the public mind (the three major factors that depend not only on the development of electric mobility but also on the whole socio-economic activity in the society's undertaking for sustainable development ) as an indispensable indication of the strategic orientation for the immediate future and perhaps even the farther future of mankind.

Current research will measure the chances of nuclear energy, first in terms of investment, then the environment and third of the society.

\section{The issue of assessing electricity, nuclear energy and electric mobility also reflected in the literature}

Without reference to any point, we will only comment on the issue of mutual dependence between the absorption of personal electric mobility and the supply of electricity required for battery charging, the fundamental research so far has focused more on the technical performance of the cars offered to the market, on the behavior of the consumer and on the quality of the loading aggregates, rather than the real need to increase the electricity supply. However, we believe that it is inappropriate to focus, for example, on the 
behavioral analysis of mobility buyers as long as the anxieties related to the maximum possible distance to go with a "full electric tank", the complications and dangers of charging, contradictory folklore information and the conservative convenience of habit with old behavioral standards.

In this case, we consider that more important than the behavioral approach of the mobility user is to analyze the power mix in terms of the potential that each of the types of source has compared to the other sources, because due to proper evaluation we can conceive an overall economic, efficient and sustainable strategy. Naturally, a pertinent analysis of all the power fields, in the sense of assigning a distinct value to each, far exceeds the scope of a research such as that taken under consideration. That is why the evaluation model we are considering here will be represented only in principle - with arbitrary data, and its practical application will only be made to the extent that other studies will reveal enough realistic data and results, in line with the scientific truth.

To emphasize only one of the difficulties in assigning the score to any of the power sources, we will still invoke two points of view, suggestively different, about renewable energy sources - and this still at a level of scientific elevation.

"In fact, research has been far from conclusive over short-and long-term impacts of the share of renewable energy in electricity production on the electricity price. Standard economic theory predicts that increasing its share may reduce the price of electricity in the short run, known as the merit-order effect." say authors Karolina Safarzyńska and Jeroen C.J.M. van den Bergh in a 2018 study (Safarzyńska, Bergh, 2018), invoking two other authors - Jensen and Skytte, who had been trapped by the interactions between energy markets and green certificates (Jensen, Skytte, 2002).

Another author, however, draws attention to the nature of stimulating renewable energies on the price of electricity: "However, in the long run, the diffusion of renewable energy has typically been financed by increasing the final electricity price paid by consumers."] (Moreno et al., 2012).

On our point of view, from colloquial talks on conferences, debates, symposiums, and from amicable daily conversations, we have built - over the years - the belief that the right price of renewable electricity would be covered by the final consumer on average only by $1 / 3$. The fluctuation and even the decrease in the incentives granted to any power source, although it may affect the socio-economic reality, will have no influence on the evaluation model.

Nuclear power instantly finds its meaning in many applications, either directly or indirectly. The first privilege of nuclear energy is its yield. This great productive potential goes beyond the capacity of any other technology that is used to produce energy and the ability to maintain a steady energy production and a clean atmosphere for current and future generations are important strengths for the future of nuclear energy. With regard to the productive efficiency of nuclear power, it is known that the decomposition of one kilogram of uranium gives off an equivalent of 21 billion kcal or equivalent to the energy produced by burning 3000 tonnes of coal. Taking advantage of this source, we can maintain and provide long-term sustainability, we can combat climate change and we can also help future generations with a clean and living planet (Ian H.-L., 2018).

Electric cars are the second part of sustainability-oriented energy binom. In 2017, the total number of electric cars in circulation was approximately 3 million, an increase of $50 \%$ over the previous year (IEA, 2018). In order to respond to this exponential trend in sales generating a corresponding demand for electricity, some steps, such as the exploration of an efficient and inexpensive source, should be considered (Ian H.-L., 2018). 
One of the four findings of the study "Reducing the CO2 emissions and the energy dependency of a large city area with zero-emission vehicles and nuclear energy", signed by the Professor of Nuclear Engineering Gonzalo Jimenez (Department of Ingeniería Energética, Universidad Politécnica de Madrid ) together with José Miguel Flores, refers precisely to the uplift that nuclear power could gain in the coming years in the context of both massive electricity demand from electric mobility and the ongoing global sustainable development project: "This replacement with zero-emissions carswould be inefficient if the electricity and/or Hydrogen needed for that fleet is generated with carbon fuels, as the emissions are still quite important in this case. The role of the Nuclear Energy in that sense could be to take part on the electricity/Hydrogen generation needed for that car fleet."] (Jimenez, G., Flores, J.M., 2014)

Nuclear power has advantages such as carbon-free emissions but also some disadvantages such as public perceptions about its future. Of all the energy sources, nuclear power has the liveliest destiny, because confidence in it is built in a relatively long time, but an accident of the size of Chernobyl or Fukushima can cause a fatal crash and collapse. Proof to this point can be, for example, the immediate political decisions of some governments to close down some or all of the atomic power plants in their countries, pressure decisions made from the population and environmental organizations.

At the same time, nuclear energy is firmly supported by specialists in the field - as it results from a double interview conducted by Investenergy.ro - a prestigious publication dedicated to the energy sector, with two "heavy ones" in the field: Mr. Dragos Gabor (CNR-CME Councilor, former director of CNE Cernavoda) and Ing. Emil Macovei (VLER, member of CNR-CME's Board of Directors, Nuclearelectrica). Both specialists consider nuclear energy to be "the only energy source capable of meeting decarbonisation targets at the same time as supply security, being stable and not dependent on price fluctuations of fossil fuels. Nuclear power ensures that the energy needs of mankind meet the "contradictory" demands of the "triple energy" as defined by the World Energy Council: it is a source of energy security because it brings a diversification of the energy mix; through its carbon-free character, is in line with the current trend of decarbonising electricity production, fully addressing the concerns of climate change prevention; the electricity produced in nuclear power plants is competitive in price compared to fossil fuel electricity, thus contributing to the supportability of electricity prices by consumers and their competitiveness on the market. " (Investenergy.ro, 2016)

In an article in 2018 entitled "The share of nuclear power in total global electricity production", the author - referring to advanced data from the International Atomic Energy Agency (IAEA), states that "... the organization's estimates also indicate increase of electricity consumption - of any kind - by $18 \%$ by 2030 and by $39 \%$ by 2050 "," ... at the end of last year (2017) the nuclear energy had a share of about $10.5 \%$ in total global electricity production "and that" the IAEA estimates that the volume of nuclear power could increase by $42 \%$ by 2030 and by $123 \%$ by 2050 "(Ionescu, 2018)

\section{Methodology}

The first problem of our practical research was to imagine the evaluation formula that of the real chances of nuclear energy as an efficient and sustainable solution to the increase in the need for electricity - for electrical mobility. However, the relevance of the formula sought should correspond - in a more democratic spirit, not only to the political and economic will, but also to the popular will. The formula sought after had to consider the two states as symbiotic, in order to assimilate them into a unitary, synthetic concept. At the same time, however, the two key elements could not be attributed to the same degree 
of importance or determination, even if at times - as we have seen above - the popular will can frustrate political and economic efforts. After several logical tests, taking into account the fact that the evaluation can not have a static character - that is, just a recording of a present reality, but much better a predictive-strategic and implicitly a dynamic one, we came to the idea that the evaluation formula to be a global index that synthesizes both the political and economic tendency of nuclear power and its public acceptance. The two components can be expressed very well by the proportional value predicted by the political and economic environment for a certain future and corresponding moment, the value given by the public environment for a whole future period. By averaging these variables, it could more accurately reflect the evolution of the domain considered, no matter how large the variations of the variables would prove to be. But, as equals can not be considered, an algorithmic difference must be applied to the two components characteristic of the global evaluation index. We have summarized this difference by assigning each fundamental component a specific index - which we call here a "factor", also expressively proportional. In order not to constrain the final perception of the result, a cento-zine-centric ratio of the resulting average was also used - a variant that even more expresses the extent of the global credit enjoyed by nuclear power in the second half of 2018.

Therefore, the formula of the index formula would be the following:

$$
N(\text { igs })=\frac{\frac{P E(i) \times f(p e)+O P(1) \times f(o p)}{2}}{100}
$$

Where

$\mathrm{N}$ (igs) - Specific global index of nuclear power,

PE (i) - The index specific to the political-economic component,

OP (i) - The index specific to the public component (s)

$\mathrm{f}$ (pe) - factor of importance for the politico-economic component,

$\mathrm{f}$ (op) - factor of importance to the public component (s).

For example, the data for the specific political-economic index can be taken from the total energy demand prediction diagram, which was published in a material signed by Monika Psenner, an energy expert. (Psenner, 2014) 


\section{Quadro energetico a livello mondiale}
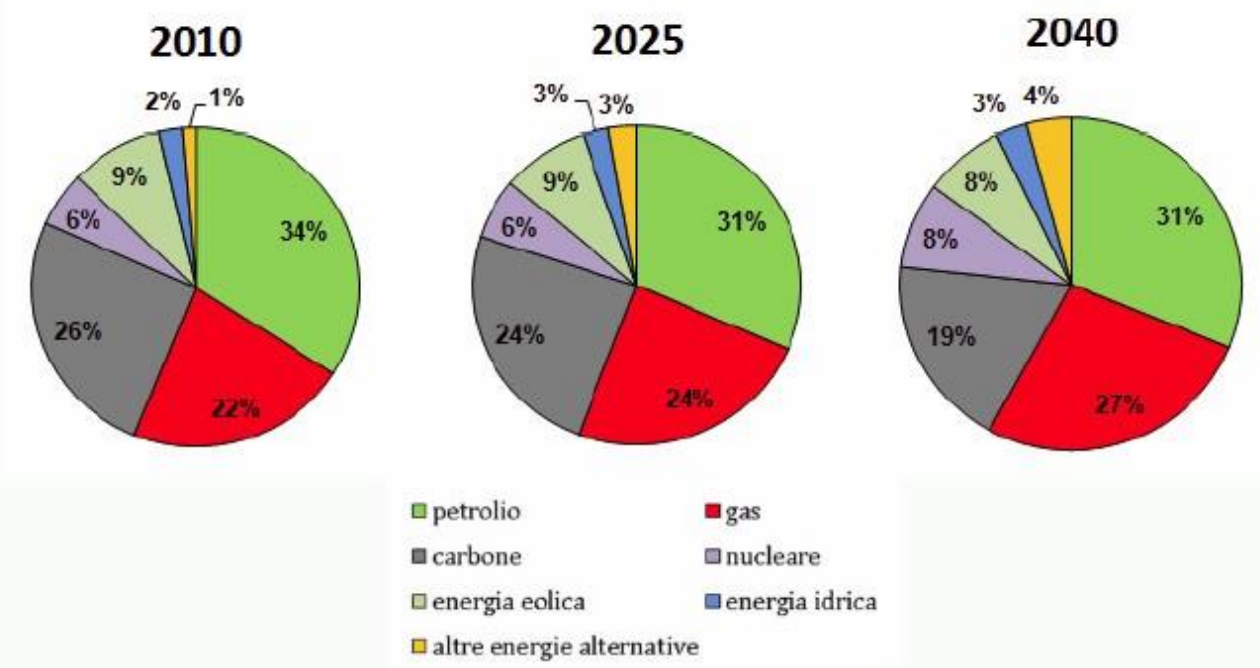

PICBE |

1232

ExxonMobile Energy Outlook 2014 (i dati si riferiscono al fabbisogno energetico primario)

Fig. 1. Global energy framework: green = energy based on petroleum products; red = energy based on natural gas; gray = coal-based energy; violet = atomic energy; green = wind energy; blue - hydraulic energy; orange - other forms of energy.

For the other information, however, we need to practice a proper questionnaire.Therefore, looking for the public representativeness to our problem, we chose the respondents according to demographic statistics, highlighted by the 2011 Population Census (National Institute of Statistics, 2011). Thus, respecting the parity of 48.6\% men and 51.4\% women, we determined that 83 men and 87 women were selected from our final sample of work, both of which were chosen from the age range 25-65 years. A second constraint we proposed was for respondents to meet the residence environment criterion. Respecting the ratio of $54 \%$ of the urban population and $46 \%$ of the population in rural areas - as evidenced by the Census, we have reached the measures of 92 urban respondents and 78 rural respondents.

Finally, the third constraint - but not necessarily in this order - was that the respondents also corresponded to the national structure according to the level of graduated education: $44.2 \%=$ primary and secondary education; $41.4 \%=$ vocational education, high school and post-secondary and $14.4 \%=$ higher education. The resulting numbers of respondents were: 75 respondents $=$ primary and secondary education; $70=$ vocational, secondary and post-secondary education, and $25=$ higher education.

The questionnaire contained 28 questions, all forms were printed and completed in the presence of the four investigators - without influencing the nature of the answers in any way. Questionnaire questions were of all types: closed, open or semi-open, with one or several variants of response, control questions or domain knowledge verification, etc.

Therefore in the end there could be 170 respondents; for 6 months, nearly 1600 people were screened. Especially for rural areas, this action was a real show of strength, but from the data collected, much information will also be useful for new research topics that we already have in mind. 
Thanks to the collected responses, it was possible to establish the index specific to the component of the public opinion, and the factors of importance specific to the two fundamental variables.

\section{Results and discussions.}

Very important for completing the specific global nuclear energy index N (igs) were the responses that highlighted two important aspects: that in the context of the global offensive of sustainability, political and economic decisions must be more important than public opinion (68\%), and that only $4.70 \%$ of respondents opted for the preponderance of nuclear energy compared to other sources in the energy strategy for a 20 year perspective into the future.

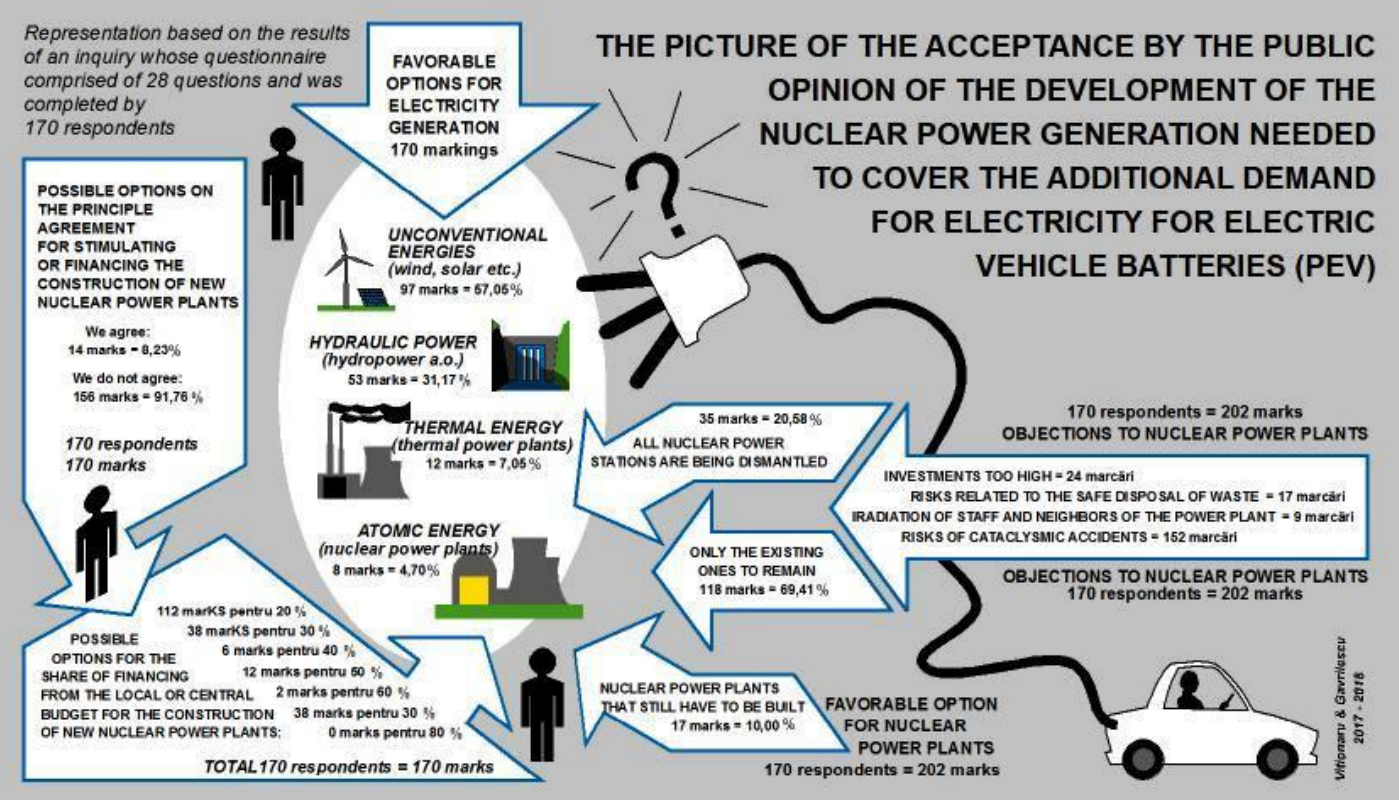

Fig.2. The picture of public acceptance of the development of nuclear power generation and the possible degree of incentive in national, union or global budgets in the context of an increased demand for electricity from electric cars.

Instead, it is possible to replace the values in the formula considered for the prospects of 2040:

$$
\mathrm{N}(\text { igs })=\frac{\frac{8 \times 68+4,7 \times 32}{2}}{100}=3,47
$$

It can be seen how much the nuclear power plant advantage is affected, due to the poor public opinion, compared to the political and economic enthusiasm. As a verification of the evaluation model, we will also calculate the global index R (igs), which includes the hydro, wind, solar, geothermal, and other energies. From this exercise we can see the extraordinary increase can give to renewable energies from the public opinion. 


$$
R(\text { igs })=\frac{\frac{15 \times 68+88,2 \times 32}{2}}{100}=38,42
$$

And in the sense of verification, by calculating the specific global index of energy based on fuels fuels (coal, oil and natural gas), we find the value of 54.61 - which does not faithfully express the greater hopes of business in these areas, yet reflects the refractory influence of the public opinion and the fact that they will still constitute around the year of 2040 a serious basis for world energy production.

Although not expressed by percentage, the specific global indexes of all electricity sources are combined, however, because the amplification due to the factors of importance is neutralized by the centhematic ratio of the basic fraction and practically they have lost some domains, but gained others.

For other times, the evaluation can be repeated. If the investigation could be repeated over five years, let's say, and if possible, as far as possible with the same interviewee, obviously others would be the results then, as otherwise would be over ten years and so on. But statistically speaking, the evolution of the interviewee's options would be an interesting and useful database of behavioral research on mobility users. Similarly, on the basis of the results of other surveys, backed about ten years ago, some responses could be assimilated to be able to retroactively calculate global indexes specific to active energy sources and implicitly pave the way for a long-term comparison.

Interesting and useful issues also emerged after grouping on their basic idea of answers to an open question about the charges to which nuclear plant managers should be obliged to:

- reengineering production to increase safety: $\rightarrow 74$ respondents;

- a permanent check of safety installations in operation: $\rightarrow 143$ respondents;

- finding the most efficient solutions for radioactive waste: $\rightarrow 64$ respondents;

- a quantum transparency about the business characteristics (correct information of clients and the whole society on all aspects that the company is reasonably and reasonably interested in): $\rightarrow 44$ respondents;

- Promoting sustainability through affordable mobility subscriptions: $\rightarrow 38$ respondents;

- Strengthening the cohesion of the entire team of the company: $\rightarrow 6$ respondents. Sustainability and transparency are not - basically speaking - far from the respondent's opinion on nuclear energy. But when they were asked to decide on which decision maker would it really depend, most of all, on the construction of new nuclear power plants, the interviewees chose:

- Business environment: $\rightarrow 40$ respondents

- Public opinion: $\rightarrow 10$ respondents

- Media: $\rightarrow 17$ respondents

- Politics: $\rightarrow 68$ respondents

- Scientific environment: $\rightarrow 35$ respondents

TOTAL responses $=170$ respondents

It should also be said that respondents do not deny the idea of substantial taxes or special taxes that could be applied to people to use their cars inside highly populated areas. The significance of such a response is the civic abnegation of most people, even though many of them have shown a low level of knowledge of energy issues. 


\section{Conclusions}

Introducing the evaluation index as a new working tool would mean a more realistic appreciation of the relative position of a field and, implicitly, a more strategic reconsideration for businesses of any kind. The best strategy for nuclear power is to improve public perceptions.

The suitability of this formula would depend on the growth of energy-based entrepreneurship in front of other power-generating technologies when presenting to society.

However, it is also necessary to inform all people in order to know as accurately and as fully as possible the advantages and shortcomings of nuclear energy as compared to other energy production processes as well as to combat any exaggeration of nuclear accidents.

Good cooperation between energy suppliers, car manufacturers and people, and paying special attention to government plans and policies will help all stakeholders meet their needs. Having a strategy for the future in terms of nuclear energy, will result in no big negative effects that affect its development.

Factors such as global population growth, the development of electric cars, climate change and the effects of global warming could make humanity more aware of the need for a zero-emission energy source, and then it would be the real chance of atomic energy to proliferate.

As a summary of the survey, it can be said that the respondents' opinions have some fluctuations. Under certain conditions, they could accept nuclear power in the country, but otherwise they would refuse. What can be drawn from this is that listening to people's needs can be one of the best approaches to assessing nuclear energy. Looking at the needs of people and meeting their needs is the first step in creating a nuclear energy assessment model.

As a final conclusion, it can be said that through the integrated approach, safety and consumer-friendly technologies, nuclear energy can be accepted as part of the change in electrical mobility.

\section{References and bibliography}

Brundtland, G. H., 1987, " Report of the World Commission on Environment and Development: Our Common Future", http://www.un-documents.net/ourcommon-future.pdf

Burlacu, G., Glodeanu, F., Ioan, R., 2006, " Energia nucleară și dezvoltarea durabilă", https://www.researchgate.net/publication/224983813_Energia_nucleara_si_dez voltarea_durabila

Ian H.-L. (2018). Nuclear Energy in the $21^{\text {st }}$ Century, $4^{\text {th }}$ Edition. World Nuclear Association.

International Energy agency, IEA, 2018. Global EV Outlook 2018. Towards cross-modal electrification. Retrieved from https://webstore.iea.org/download/direct/1045?fileName=Global_EV_Outlook_ 2018.pdf

Ionescu, T., 2018, "Ponderea la care a ajuns energia nucleară în totalul producţiei globale de electricitate", https://www.mediafax.ro/economic/ponderea-la-carea-ajuns-energia-nucleara-in-totalul-productiei-globale-de-electricitate-17480949

Jensen, S.G., Skytte, K., 2002, "Interactions between the power and green certificate Markets", Energy Policy 30: 425-435. 
Jimenez, G., Flores, J.M., (2014). Reducing the CO2 emissions and the energy dependence of a large city area with zero- emission vehicles and nuclear energy, Progress in Nuclear Energy. Progress in Nuclear Energy, 1-8.

Moreno, B., Lopez, A.J., Garcia-Alvarez, M.T., 2012, "The electricity prices in the European Union. The role of renewable energies and regulatory electric market reforms", Energy 48: 307-313.

Psenner, M.,2014, " Fabbisogno energetico mondiale: situazione attuale e prospettive future, di Redazione Green Planner - città: Bolzano - pubblicato il: 30 Gennaio 2014, https://www.greenplanner.it/2014/01/30/fabbisogno-energeticomondiale-situazione-attuale-e-prospettive-future/

Institutul Național de Statistică, 2011, "Rezultate definitive ale Recensământului Populaţiei şi al Locuinţelor - 2011 (caracteristici demografice ale populaţiei), http://www.recensamantromania.ro/wpcontent/uploads/2013/07/REZULTATE-DEFINITIVE-RPL_2011.pdf

Investenergy.ro, 2016, "Nevoia de energie nucleară: singura sursă care îndeplinește obiectivele de decarbonizare concomitent cu siguranța în furnizare", https://www.investenergy.ro/dialogurile-investenergy-nevoia-de-energienucleara-singura-sursa-care-indeplineste-obiectivele-de-decarbonizareconcomitent-cu-siguranta-in-furnizare/

Safarzyńska, L., Bergh, J.C.J.M. van den, 2018, "A higher rebound effect under bounded rationality: Interactions between car mobility and electricity generation", PII: S0140-9883(18)30224-X ;DOI: doi:10.1016/j.eneco.2018.06.006; Reference: ENEECO 4057.

Soo-Ho Park, et.al. (2016). Can Renewable Energy Replace Nuclear Power In Korea? An Economic Valuation Analysis. Nuclear Engineering and Technology 48 (2016) 559-571.

World Health Organisation. (2015). Registered vehicles. Data by country. Romania. Retrieved fromhttp://apps.who.int/gho/data/node.main.A995

World Resources Institute, Climate Analysis Indicators Tool. (2008). Climate Change and C02. Retrieved from http://oica.net/wp-content/uploads/climate-change-andco2-brochure.pdf 